\title{
Avaliação da brotação de tubérculos de Cyperus rotundus pelo teste de respiração
}

\author{
Evaluation of Cyperus rotundus tubers sprouting by breathing test
}

\author{
Ferdinando Marcos Lima Silva ${ }^{1}$, Edivaldo Domingues Velini ${ }^{2}$, Caio Vitagliano Santi Rossi ${ }^{3}$, \\ Eduardo Negrisoli ${ }^{4}$, Marcelo Rocha Corrêa ${ }^{4}$
}

\begin{abstract}
Resumo - O teste de respiração é um teste bioquímico, indireto, que permite medir a quantidade de oxigênio consumida, sendo bastante utilizado na medição da taxa de respiração de sementes e na respiração edáfica. O objetivo do trabalho foi desenvolver e validar uma metodologia para verificar a brotação de tubérculos de tiririca (Cyperus rotundus) através de teste de respiração. Para o desenvolvimento da metodologia, foram realizados testes em que os tubérculos sofreram um pré-condicionamento com glicose, ácido-giberélico ou com água destilada, na tentativa de homogeneizar a brotação. $\mathrm{O}^{\mathrm{CO}_{2}}$ produzido pela respiração dos tubérculos era capturado por $\mathrm{NaOH}$ e a taxa de respiração foi determinada por titulação utilizando $\mathrm{HCl}$. Para a validação da metodologia utilizou-se o herbicida glyphosate em cinco dosagens, o qual foi aplicado em vasos infestados com $C$. rotundus no estágio de préflorescimento. Os resultados obtidos demonstraram que não houve diferença significativa na somatória da taxa respiratória quanto ao uso de glicose ou água no pré-condicionamento e uma redução com uso de ácido-giberélico. No período de 48-96 horas, a produção de $\mathrm{CO}_{2}$ foi decrescente com o aumento da dose de glyphosate, assim como a porcentagem de brotação dos tubérculos. Portanto a metodologia proposta pode ser utilizada como uma técnica rápida e simples para prever a porcentagem de brotação de tubérculos.
\end{abstract}

Palavras-chave: $\mathrm{CO}_{2}$, glyphosate, tiririca.

\begin{abstract}
The breath test is a indirect biochemical test that means to measure the amount of oxygen consumed, has been extensively used in measuring the respiration rate of seeds and soil respiration. The objective was to develop and validate a methodology to assess sprouting of purple nutsedge (Cyperus rotundus) tubers by breathing test. In order to develop the methodology, tests were carried out with the objective of homogenizing the sprouting. In these tests the tubers suffered a preconditioning with glucose, gibberelic acid or with distilled water. In addition to validate the methodology it was used the glyphosate in five rates that was sprayed in pots infested with $C$. rotundus at the full development (before flowering). The results obtained

\footnotetext{
${ }^{1}$ Eng. Agr. MSc Doutorando, Dep. De Agricultura FCA/Unesp, Fazenda Experimental Lageado, Caixa Postal 237, 18603-970, Botucatu-SP, ferdinando.silva@yahoo.com.br;

${ }^{2}$ Prof. Dr., Dep. De Agricultura FCA/Unesp, Fazenda Experimental Lageado, Caixa Postal 237, 18603-970;

${ }^{3}$ Eng. Agr. Dr., Milenia Agrociências S.A., Uberlândia-MG;

${ }^{4}$ Eng.Agr. Dr., Dep. De Agricultura FCA/Unesp, Fazenda Experimental Lageado, Caixa Postal 237, 18603-970, Botucatu-SP.
} 
showed that there is no significant difference in the sum of the breathed amount considering the use of glucose or water in the preconditioning and a reduction in use of gibberellic acid. In the period of 48-96 hours the $\mathrm{CO}_{2}$ production was decreased with the increased glyphosate rate, as well as the percentage of sprouting. Therefore the proposal methodology can be used as a fast and simple technique to foresee the percentage of sprouting tubers.

Keywords: $\mathrm{CO}_{2}$, glyphosate, purple nutsedge.

\section{Introdução}

A tiririca é uma planta cosmopolita, que possui fácil adaptação as condições climáticas encontradas em regiões tropicais e subtropicais, fazendo desta uma espécie altamente agressiva e competidora com as plantas cultivadas. Segundo Lorenzi (2000), a tiririca é a planta daninha mais disseminada e a mais nociva do globo terrestre, sendo encontrada no Brasil em diversas culturas. Guimarães (1981) complementa que esta espécie possui alta capacidade de reprodução, rápida disseminação e grande velocidade de crescimento e desenvolvimento, além de adaptar-se a diversos tipos de solos e climas sendo muito resistente a condições extremas de calor, seca, umidade, ou falta de aeração. Segundo Durigan et al. (2006), a tiririca é uma planta daninha de difícil erradicação e, por conseqüência, as áreas agrícolas infestadas com esta espécie crescem continuamente em curto espaço de tempo.

Hernandez et al. (2001) citam que o principal método de controle das plantas daninhas é o químico, por meio da aplicação de herbicidas, sendo estes utilizados na préemergência e pós-emergência dessas infestantes. Para que se obtenha um bom controle de plantas daninhas, é necessário o conhecimento da biologia destas espécies, pois desta maneira é possível uma melhor escolha do herbicida a ser utilizado, determinando também a melhor época e a modalidade de aplicação, bem como o seu uso racional, alcançando então o máximo de eficácia (Kogan, 1987). Dentre os herbicidas utilizados para o controle da tiririca, o glyphosate apresenta boa ação no controle da tiririca, pois transloca-se até os tubérculos próximos ao bulbo basal, proporcionando redução significativa na rebrota (Freitas et al., 1997).

O teste de respiração é um teste bioquímico, indireto, que permite medir a quantidade de oxigênio consumida ou o quociente respiratório. Este é bastante utilizado na medição da taxa de respiração de sementes e na respiração de organismos presentes no solo, tendo como princípio básico a reação que ocorre entre $\mathrm{CO}_{2}$ e hidróxido de sódio com a produção de carbonato, o qual pode ser quantificado pelo método de titulometria, utilizando-se ácido clorídrico. Popinigis (1985) relatou que a primeira atividade metabólica, acompanhando a reidratação da semente, é o aumento da velocidade respiratória que, de valores ínfimos, sobe a níveis bastante elevados, poucas horas após o início da embebição.

Crispim et al. (1994) citam que dentre as diferentes formas de verificação da qualidade fisiológica de sementes, o processo de respiração tem merecido especial atenção, pela alta relação entre este fenômeno e a qualidade da semente. Desta forma, a liberação de $\mathrm{CO}_{2}$ no processo de respiração é a principal variável para correlacionar com a qualidade das sementes.

Grisi (1978) demonstrou a validade do método químico de avaliação de respiração edáfica pela reação de $\mathrm{CO}_{2}$ com hidróxido de potássio, onde pode-se verificar a coerência do teste de respiração com taxas de decomposição 
de celulose em solos com diferentes teores de matéria orgânica.

Portanto, o presente trabalho teve como objetivo desenvolver e validar uma metodologia para verificar a brotação de tubérculos de tiririca (Cyperus rotundus) através de teste de respiração.

\section{Material e Métodos}

$\mathrm{O}$ experimento foi instalado em casa de vegetação, no Núcleo de Pesquisas Avançadas em Matologia (NuPAM), pertencente ao Departamento de Produção Vegetal, da FCA/UNESP, Botucatu-SP. O delineamento experimental utilizado foi inteiramente casualizado, com quatro repetições. $\mathrm{O}$ experimento foi dividido em duas partes, sendo a primeira parte para o desenvolvimento e a segunda para a validação da metodologia. As metodologias utilizadas foram descritas por Jenkinson \& Powlson (1976), Crispim et al. (1994) e Corrêa et al. (2005).

As unidades experimentais corresponderam a vasos de polietileno com capacidade para 2 litros de substrato, nos quais os tubérculos foram colocados, em profundidade de $3 \mathrm{~cm}$, após um período de précondicionamento em água destilada por 12 horas. Como substrato para os tubérculos utilizou-se areia lavada e esterilizada sendo mantida a $60 \%$ da máxima capacidade de retenção de água ao longo do período. Para quantificação do $\mathrm{CO}_{2}$ liberado, foi colocado, dentro de cada vaso, um frasco contendo 20 $\mathrm{mL}$ de solução de $\mathrm{NaOH}$ a $1 \quad \mathrm{~N}$. Posteriormente, os vasos foram lacrados e incubados em ausência de luz e mantidos sob temperatura média de $26^{\circ} \mathrm{C}$.

No desenvolvimento da metodologia, utilizou-se 50 tubérculos em cada repetição. $\mathrm{Na}$ tentativa de homogeneizar a brotação, conduziu-se três tratamentos em que os tubérculos sofreram um pré-condicionamento com: glicose a $1 \%$, ácido giberélico a $0,05 \%$ ou água destilada. $\mathrm{O}$ pré-condicionamento consistiu em manter os tubérculos imersos nas soluções por um período de 12 horas antes de serem incubados. A leitura do $\mathrm{CO}_{2}$ foi realizada em quatro períodos de incubação: 0 $24,24-48,48-96$ e $96-120$ horas.

Após os períodos de incubação, os recipientes com $\mathrm{NaOH}$ foram retirados para determinação da taxa de respiração através de titulação. Inicialmente adicionou-se a esta solução cinco gotas de solução alcoólica de fenolftaleína a $0,1 \%$, realizando-se titulação com $\mathrm{HCl}$ a $0,65 \mathrm{~N}$. Após a primeira viragem (mudança de coloração da solução), foram adicionados cinco gotas de solução alcoólica de di-metil-orange a $0,5 \%$. Quando a segunda viragem ocorreu, anotou-se a diferença de volume de $\mathrm{HCl}$ contido na bureta, utilizado durante as duas viragens. Esta diferença de volume corresponde ao número de equivalentes de $\mathrm{CO}_{2}$ produzidos e retidos no recipiente com $\mathrm{NaOH}$ na forma de carbonato, depois de descontado o valor equivalente obtido no tratamento referencial (branco).

A quantificação do $\mathrm{CO}_{2}$ liberado foi calculada pela seguinte expressão:

$$
\begin{gathered}
\text { g CO} 2 \text { liberado }=\mathrm{N}_{\text {eq }} \mathrm{CO}_{2} \times 22 \\
\text { em que } \mathrm{N}_{\text {eq }} \mathrm{CO}_{2}=\mathrm{V}_{\text {(titulado) }}(\mathrm{mL}) \times 0,65
\end{gathered}
$$

Realizou-se testes nos quais foram determinados o teor de umidade média dos tubérculos e o teor de carbono dos mesmos. Assim, permitiu apresentar os resultados em miligramas de dióxido de carbono por grama de carbono do tubérculo ( $\mathrm{mg} \mathrm{CO}_{2} / \mathrm{g} \mathrm{C}$ ).

Para a validação da metodologia, seis tubérculos de $C$. rotundus foram plantados em vasos com capacidade para dois litros de substrato, os quais foram preenchidos com Latossolo Vermelho distrófico (LVd). Cinco doses de glyphosate $(0,180,360,720$ e $1440 \mathrm{~g}$ e.a. $\mathrm{ha}^{-1}$ ) foram aplicadas sobre os vasos infestados com tiririca no estágio de pré- 
florescimento, por ser a época que afeta a maior porcentagem de tubérculos (Durigan et al., 2005). Após um mês da aplicação, os tubérculos foram coletados para as avaliações por dois métodos (teste de respiração e teste de brotação).

Para o teste de respiração os tubérculos coletados passaram por um précondicionamento, sendo imersos em água destilada por 12 horas e pesados antes da incubação nas unidades experimentais. Realizou-se a leitura do $\mathrm{CO}_{2}$ liberado em três períodos de incubação (0 - 24, 24 - 48 e 48 - 96 horas). Após os períodos de incubação, os recipientes com $\mathrm{NaOH}$ foram retirados para determinação da taxa de respiração através de titulação, segundo os procedimentos já descritos anteriormente.

No caso do teste de brotação, os tubérculos eram mantidos em vasos com areia lavada e esterilizada com $60 \%$ da máxima capacidade de retenção. Os vasos foram incubados em ausência de luz a uma temperatura média de $26^{\circ} \mathrm{C}$. Realizou-se a contagem do número de tubérculos brotados e os resultados obtidos foram apresentados em porcentagem de brotação.

Tabela 1. Resultados obtidos de $\mathrm{CO}_{2}$ liberado $\left(\mathrm{mg} \mathrm{CO}_{2} / \mathrm{g} \mathrm{C}\right.$ ) pelos tubérculos de tiririca $(C$. rotundus), em função da solução utilizada para o pré-condicionamento nos diferentes períodos de incubação. Botucatu-SP, 2006.

\begin{tabular}{cccccc}
\hline \multirow{2}{*}{ Tratamento } & \multicolumn{5}{c}{ Periodos de leitura (horas) } \\
\cline { 2 - 6 } & $0-24$ & $24-48$ & $48-96$ & $96-120$ & Acumulado \\
\hline 1-Ácido Giberélico & $6,01 \mathrm{a}$ & $5,58 \mathrm{~b}$ & $14,41 \mathrm{a}$ & $21,80 \mathrm{a}$ & $47,80 \mathrm{a}$ \\
2-Glicose & $8,69 \mathrm{~b}$ & $5,86 \mathrm{~b}$ & $15,75 \mathrm{~b}$ & $25,12 \mathrm{~b}$ & $54,58 \mathrm{~b}$ \\
3-Água Destilada & $6,89 \mathrm{a}$ & $5,11 \mathrm{a}$ & $16,03 \mathrm{~b}$ & $26,55 \mathrm{~b}$ & $55,43 \mathrm{~b}$ \\
\hline F & $15,53^{* *}$ & $7,52^{* *}$ & $5,74^{*}$ & $9,07 * *$ & $14,50^{* * *}$ \\
CV (\%) & 9,66 & 5,01 & 4,69 & 6,62 & 4,17 \\
DMS & 0,90 & 0,36 & 0,93 & 2,10 & 2,85 \\
\hline
\end{tabular}

Médias seguidas da mesma letra não diferem significativamente entre si, pelo teste $\mathrm{t}$ ao nível de $10 \%$ de probabilidade. * significativo a $5 \% \mathrm{e}^{* *}$ significativo a $1 \%$ de probabilidade pelo teste $\mathrm{F}$.

Rev. Bras. Herb., v.8, n.2, p.37-43, mai./ago. 2009 
O método demonstrou eficiência no estudo da quantificação da respiração de tubérculos de tiririca, apresentando melhores resultados no período de 48 a 96 horas de incubação, devido a uma taxa de respiração considerável, podendo também neste período medir efetivamente a brotação dos tubérculos. Fato este que não pode ser ressaltado no último período de leitura (96-120 horas de incubação), pois apesar de apresentar a maior taxa de respiração, a demanda de tempo para aquisição de resultados é maior, e isto faz com que as plantas apresentem grande número de

Tabela 2. Resultados obtidos de $\mathrm{CO}_{2}$ liberado $\left(\mathrm{mg} \mathrm{CO}_{2} / \mathrm{g} \mathrm{C}\right.$ ) pelos tubérculos de tiririca $(C$. rotundus), em função de diferentes doses de glyphosate. Botucatu-SP, 2006.

\begin{tabular}{cccccc}
\hline Tratamento & $\begin{array}{c}\text { Dose } \\
\text { (g e.a. ha }\end{array}$ & \multicolumn{4}{c}{ Períodos deleitura (horas) } \\
\cline { 3 - 6 } & - & $0-24$ & $24-48$ & $48-96$ & Acumulado \\
\hline 1-Testemunha & - & $5,73 \mathrm{ab}$ & $4,34 \mathrm{a}$ & $16,14 \mathrm{~d}$ & $26,22 \mathrm{~b}$ \\
2- glyphosate & 180 & $7,10 \mathrm{~b}$ & $5,40 \mathrm{~b}$ & $11,72 \mathrm{c}$ & $24,22 \mathrm{~b}$ \\
3- glyphosate & 360 & $9,15 \mathrm{c}$ & $5,56 \mathrm{~b}$ & $8,92 \mathrm{~b}$ & $23,63 \mathrm{~b}$ \\
4- glyphosate & 720 & $6,44 \mathrm{~b}$ & $4,38 \mathrm{a}$ & $7,29 \mathrm{ab}$ & $18,11 \mathrm{a}$ \\
5-glyphosate & 1440 & $5,01 \mathrm{a}$ & $3,94 \mathrm{a}$ & $6,29 \mathrm{a}$ & $15,24 \mathrm{a}$ \\
\hline F & & $7,61^{*}$ & $3,34^{*}$ & $15,65^{* *}$ & $8,13^{* *}$ \\
CV (\%) & 17,16 & 16,5 & 19,89 & 15,03 \\
DMS & 1.42 & 0.97 & 2.48 & 4.00 \\
\hline
\end{tabular}

Médias seguidas da mesma letra não diferem significativamente entre si, pelo teste t ao nível de $10 \%$ de probabilidade. * significativo a $5 \%$ e ** significativo a $1 \%$ de probabilidade pelo teste $\mathrm{F}$.

As maiores taxas respiratórias dos tratamentos que receberam a aplicação de glyphosate, nos períodos iniciais do teste $(0$ 24 e 24 - 48 horas de incubação), em relação à testemunha, pode ser devido à presença de microrganismos atuantes no processo de decomposição dos tubérculos mortos ou que estavam morrendo.

As porcentagens de brotação dos tubérculos em função das diferentes doses de glyphosate (Figura 1) ajustaram-se ao modelo de regressão polinomial quadrático, demonstrando que o aumento da dose de glyphosate implicou na redução da porcentagem de brotação, demonstrando o folhas emitidas, dificultando a continuidade do estudo.

Os resultados da validação da metodologia indicaram que os tubérculos provenientes de parcelas com aplicação de glyphosate apresentaram maior liberação de $\mathrm{CO}_{2}$ nos períodos de 0 - 24 e 24 - 48 horas de incubação (Tabela 2). O inverso foi observado para o período de 48 - 96 horas de incubação, no qual a produção de $\mathrm{CO}_{2}$ foi decrescente com o aumento da dose de glyphosate. efeito do herbicida sobre a brotação dos tubérculos.

Desta forma, quando comparados os dados do teste de respiração, no período de 48 - 96 horas de incubação, e do teste de brotação pode-se observar que ambos têm comportamento semelhante em resposta ao aumento da dosagem de glyphosate, ocorrendo similar redução na taxa de respiração e no percentual de brotação.

Durigan et al. (2005) obtiveram $71 \%$ de tubérculos afetados por glyphosate, na dose de 720 g e.a. ha ${ }^{-1}$, quando aplicado no préflorescimento, resultado semelhante ao encontrado neste estudo quando na mesma 
dose obteve-se brotação de 36, $94 \%$ dos tubérculos.

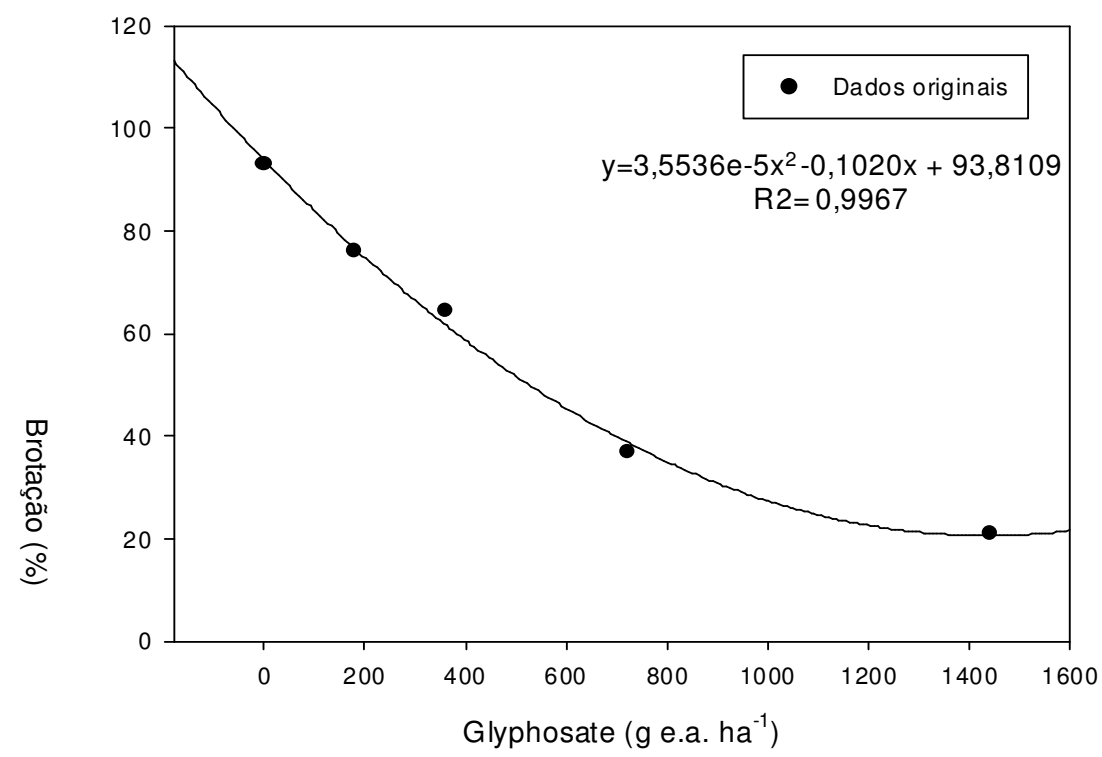

Figura 1. Porcentagem de brotação dos tubérculos de $C$. rotundus após aplicação do herbicida glyphosate em diferentes doses. Botucatu-SP, 2006.

Conforme resultados obtidos por Corrêa et al. (2005) onde o teste mostrou-se viável no estudo de decomposição de plantas aquáticas, o teste de respiração demonstrou ser eficiente no estudo da quantificação da respiração de tubérculos de tiririca ( $C$. rotundus), apresentando melhores resultados no período de 48 a 96 horas de incubação, sendo que o pré-condicionamento para homogeneização dos tubérculos pode ser feito diretamente com água destilada. A produção de $\mathrm{CO}_{2}$ no intervalo de 48 - 96 horas de incubação pode ser utilizada como uma técnica rápida e simples para prever a porcentagem de brotação de tubérculos, podendo ser associada a outros métodos que determinem a viabilidade dessas estruturas.

\section{Conclusões}

Os resultados demonstram que a metodologia para verificar da brotação de tubérculos de tiririca (Cyperus rotundus) através de teste de respiração pode ser utilizada para uma avaliação precoce da eficácia do glyphosate no controle de tiririca.

\section{Agradecimentos}

À FAPESP, Fundação de Amparo à Pesquisa do Estado de São Paulo, pelo apoio financeiro recebido. 


\section{Referências}

CORRÊA, M.R. et al. Avaliação da decomposição de plantas aquáticas no solo através da liberação de $\mathrm{CO}_{2}$. Planta Daninha, v.23, n.2, p.243-248, 2005.

CRISPIM, J.E. et al. Determinação da taxa de respiração em sementes de soja pelo método da titulação. Pesquisa Agropecuária Brasileira, v.29, n.10, p.1517-1521, 1994.

DURIGAN, J.C. et al. Manejo integrado da tiririca na produtividade de cana-de-açúcar. Planta Daninha, v.24, n.1, p.77-81, 2006.

DURIGAN, J.C.; CORREIA, N.M.; TIMOSSI, P.C. Estádios de desenvolvimento e vias de contato e absorção dos herbicidas na inviabilização de tubérculos de Cyperus rotundus. Planta Daninha, v.23, n.4, p.621626, 2005.

FREITAS, R.S. et al. Efeitos do flazassulfuron e do glyphosate em aplicações única e seqüencial sobre o controle da tiririca (Cyperus rotundus). Ceres, v.44, n.256, p.597603, 1997.

GRISI, B.M. Método químico de medição da respiração edáfica: alguns aspectos técnicos. Ciência e Cultura, v.30, n.1, p.82-88, 1978.

GUIMARÃES, S.C. Influência da idade de corte e de aditivos na ação de glyphosate sobre a tiririca (Cyperus rotundus L.). Viçosa: UFV, 1981. 98p. (DissertaçãoMestrado em Fitotecnia).

HERNANDEZ, D.D.; ALVES, P.L.C.A.; MARTINS, J.V. F. Influência do resíduo de colheita de cana-de-açúcar sem queima sobre a eficiência do imazapic e imazapic + pendimethalin. Planta Daninha, v.19, n.3, p.419-426, 2001.

JENKINSON, D.S.; POWLSON, D.S. The effects of biocidal treatments on metabolism in soil. V. A method for measuring soil biomass.
Soil Biology and Biochemistry, v.8, n.3, p.209-213, 1976.

KOGAN, M.A Ecofisiologia da tiririca, sua competição e efeitos alelopáticos com canade-açúcar. In: Eptam Herbicida Seletivo. Campinas: Stauffer Produtos Químicos, 1987. p. 1-7.

LORENZI, H. Plantas daninhas do Brasil: terrestres, aquáticas, parasitas e tóxicas. 3. ed. Nova Odessa: Plantarum, 2000. 608 p.

POPINIGIS, F. Fisiologia da semente. 2. ed. Brasília: Ministério da Agricultura AGIPLAN, 1985. p.97-103. 